\title{
A Molecular Picture of the Adsorption of Glycine in Mesoporous Silica through NMR Experiments Combined with DFT-D Calculations
}

Nicolas Folliet, ${ }^{\dagger, \ddagger}$ Christel Gervais, ${ }^{*},{ }^{\dagger}$ Dominique Costa, ${ }^{\S}$ Guillaume Laurent, ${ }^{\dagger}$ Florence Babonneau, ${ }^{\dagger}$ Lorenzo Stievano, " Jean-François Lambert, ${ }^{\ddagger}$ and Frederik Tielens ${ }^{*}+\frac{+}{*}$

${ }^{\dagger}$ UPMC Univ Paris 06, \& CNRS Laboratoire de Chimie de la Matière Condensée de Paris, Collège de France, 11 place Marcelin Berthelot, F-75005 Paris, France

‡UPMC Univ Paris 06, UMR 7197, Laboratoire de Réactivité de Surface, Casier 178, 3, Rue Galilée, F-94200 Ivry-sur-Seine, France

${ }^{\S}$ Laboratoire de Physico-Chimie des Surfaces, Ecole Nationale Supérieure de Chimie de Paris - UMR 7045, 11 rue Pierre et Marie Curie, F-75231 Paris Cedex, France

"ICGM - UMR5253- Equipe AIME, Université Montpellier II, 2 Place Eugène Bataillon - CC 1502, 34095 Montpellier Cedex 5, France

Supporting Information

ABSTRACT: The adsorption behavior of the amino acid glycine in mesoporous silica has been investigated using a combination of quantum chemical calculations and NMR spectroscopy experiments. Glycine adsorption on two representative sites of an amorphous silica surface, vicinal silanols and a silanol nest, was investigated by DFT-D. The effect of water coadsorption on the energetics of adsorption and NMR shifts was characterized. It was found that the silanol nest is a more favorable site for glycine adsorption due to a local increased $\mathrm{H}$-bond density. Co-adsorption with water is also favored, especially a water molecule between a $\mathrm{SiOH}$ and the ammonium moiety. NMR chemical shifts computed on these models fall into the observed ${ }^{13} \mathrm{C}$ and ${ }^{15} \mathrm{~N}$ experimental range, suggesting that the presence of different energetically comparable adsorption configurations cannot be excluded.

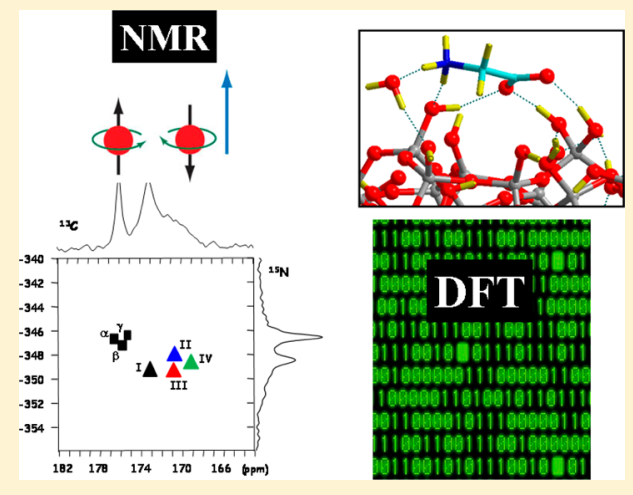

\section{INTRODUCTION}

An increased interest has been shown in the past for the synthesis of templated inorganic materials due to their potential applications in catalysis and controlled release. ${ }^{1,2}$ These applications are closely related to the binding of biomolecules on inorganic surfaces, but questions related to the nature of interfacial interactions still need to be addressed. Studies on simple model systems are thus needed for a thorough understanding of more complex systems. This is the reason why building block approaches are developed by some groups in order to understand the adsorption of biomolecules (from amino acids to proteins) on solid surfaces. ${ }^{3}$ To this respect, glycine, the smallest and simplest amino acid, simultaneously exhibits both carboxylate/carboxylic and amine/ammonium moieties and, thus, represents a good reference object for other more complex biological molecules. Indeed, a number of papers appeared in recent years concerning the adsorption of glycine or other amino acids on oxide surfaces, ${ }^{4}$ and a review specially devoted to amino acids on silica has recently been published. ${ }^{13}$

Recent developments in solid-state NMR open promising perspectives for the detailed characterization of such interactions between small molecules and inorganic surfaces. ${ }^{6}$ This local spectroscopic technique can establish "dialogues" between nuclear spins. In that sense, solid-state NMR is a perfect tool of investigation for the hybrid organic-inorganic interfaces in nanomaterials. NMR spectroscopy and more particularly dipolar recoupling experiments were used recently to identify interacting moieties in alanine adsorbed on a mesoporous silica SBA-15 surface, $^{7}$ and later in glycine adsorbed on the same support. ${ }^{8}$ In both cases, the authors show that the ammonium group interacts directly with silanols (predominantly terminal ones) on the surface while the carboxylates seem to freely reorient.

There has been a continuous increase in the number of $a b$ initio theoretical studies on the adsorption of amino acids or organic molecules on several oxide surfaces such as amorphous or crystalline silica, ${ }^{9-13}$ alumina, ${ }^{14} \mathrm{ZnO},{ }^{15,16} \mathrm{Cr}_{2} \mathrm{O}_{3}{ }^{17,18}$ $\mathrm{TiO}_{2}{ }^{19-25}$ and hydroxyapatite. ${ }^{5,26-29}$ Even glycine, the simplest amino acid, may present different adsorption mechanisms on an oxide surface: first, it may be adsorbed in neutral, cationic, zwitterionic, or anionic forms according to the protonation state of the amine and carboxylate groups $\left(\mathrm{NH}_{2}-\mathrm{CH}_{2}-\right.$ $\mathrm{COOH}, \mathrm{NH}_{3}{ }^{+}-\mathrm{CH}_{2}-\mathrm{COOH}, \mathrm{NH}_{3}{ }^{+}-\mathrm{CH}_{2}-\mathrm{COO}^{-}, \mathrm{NH}_{2}-$ $\mathrm{CH}_{2}-\mathrm{COO}^{-}$, respectively). Second, adsorption may be driven by covalent bonding, H-bonding with the surface, ionic

Received: December 11, 2012

Revised: January 25, 2013

Published: January 28, 2013 
interactions, self-assembly between the biomolecules, and any combination of those possibilities. ${ }^{4}$

Most of the $a b$ initio studies of glycine adsorption were performed in the absence of solvent; that is, they are relevant to adsorption from the gas phase. However, the presence of solvent molecules (e.g., water) may significantly influence glycine adsorption equilibria and kinetics. On the one hand, the solvation of the biomolecule may hinder its interaction with the surface. On the other hand, the coadsorption of water and biomolecule may actually contribute to stabilizing the adsorbed form. Water may also lower the kinetic barriers for conformational changes or proton transfers. Only few ab initio studies of the adsorption of amino acids on surfaces in the presence of water as a solvent have been undertaken, due to the extensive cost of ab initio molecular dynamics (MD) calculations and of the very short time periods simulated during a calculation (a few picoseconds). Marx and co-workers studied the adsorption of glycine on pyrite at the solid-liquid interface. ${ }^{30-33}$ In this series of studies, glycine was found to be preferentially solvated in the liquid phase and not adsorbed on the ideal surface of pyrite, while the presence of sulfur vacancies caused a specific adsorption involving coordination of the carboxylate to iron ions, with or without coadsorption of water. On rutile $\mathrm{TiO}_{2}$, Langel and Menken ${ }^{23}$ investigated the adsorption of glycine, methionine, cysteine and serine. MD simulation revealed that the most stable adsorbed form of the amino acids involved coordination of the carboxylate moiety to two $\mathrm{Ti}^{4+}$ centers, in a bridging position (in addition, cysteine could also coordinate through its deprotonated thiol group and thus behave as a bidentate ligand). An adsorption mechanism involving carboxylate coordination to $\mathrm{Ti}^{4+}$ was also found to be operating for glycine (Gly) on rutile (110). ${ }^{34}$ We have recently explored the adsorption mechanism of glycine on Boehmite (AlOOH). ${ }^{35}$ Inner-sphere adsorption (by unidentate carboxylate coordination to $\mathrm{Al}^{3+}$ ) was favored over outer-sphere, with adsorption energies of -160 and $-20 \mathrm{~kJ} \cdot \mathrm{mol}^{-1}$, respectively.

On silica, in contrast, the favored amino acid adsorption mechanisms do not involve coordination, or covalent bond formation. Recently, Nonella and Seeger ${ }^{36}$ investigated the alanine-silica interaction in the presence of bulk water by means of DFT-MD. They found that the strongest interaction occurred for a positively charged alanine ion and a negatively charged silica surface. The formation of $\mathrm{H}$-bonds with isolated silanols on $\mathrm{Gly} / \mathrm{SiO}_{2}$ systems was found to be weakly exothermic, ${ }^{9,11}$ whereas the formation of a $\mathrm{H}$-bond network with a specific silanol nest could induce strong bonds of glycine with the surface. "Microsolvating" water molecules were added to the system to understand the effect of water coadsorption. Several first principles molecular dynamics runs indicated that in the dominant conformation the $\mathrm{COO}^{-}$moiety is directly $\mathrm{H}$-bonded to one geminal $\mathrm{SiOH}$ group on the surface, whereas $\mathrm{NH}_{3}{ }^{+}$interacts with water molecules far from the surface. ${ }^{10}$ Zhao et al. ${ }^{37}$ and Walsh et al. ${ }^{38}$ obtained very similar results: the dominant configuration exhibits the $\mathrm{COO}^{-}$ group pointing toward the surface in direct contact with geminal $\mathrm{SiOH}$ groups, while the $\mathrm{NH}_{3}{ }^{+}$prefers to interact with bulk water, away from the surface. Interesting data concerning the effect of increasing numbers of microsolvating water molecules on the structure of glycine interacting with an edingtonite $\mathrm{SiO}_{2}$ surface can also be found in the work of Rimola et al. ${ }^{39}$

The ideal way to thoroughly understand adsorption at the solid liquid interface, however, is to couple the experimental and the theoretical approaches by performing an ab initio assisted interpretation of spectroscopic data. For instance, the spectroscopic data obtained by NMR and the theoretical structural models of glycine adsorption can be associated by performing first principles calculations of the NMR parameters, starting from structural models based on DFT. For that purpose, the GIPAW (Gauge Included Projected Augmented Wave) method, first proposed by Pickard and Mauri, ${ }^{40}$ is now considered as a tool of choice for solid state NMR calculations (in the frame of DFT and under periodic boundary conditions). ${ }^{41}$ The combined theoretical/experimental approach $^{42,43}$ and in particular the DFT structural modeling/ solid state NMR/GIPAW approach represents a very useful tool for the detailed characterization of organic-inorganic interfaces ${ }^{44}$ and seems therefore adequate for a detailed study of the glycine-silica interface at an atomic level.

In this contribution, a mesoporous MCM-41 silica ${ }^{45,46}$ was prepared and loaded with glycine. Solid-state NMR was then used for the investigation of the adsorbed amino acid and in particular for investigating the proximities between silanols, water molecules and glycine molecules using two-dimensional ${ }^{1} \mathrm{H}-\mathrm{X}$ HETCOR CP MAS experiments $\left(\mathrm{X}={ }^{13} \mathrm{C},{ }^{15} \mathrm{~N}\right.$, and ${ }^{29} \mathrm{Si}$ ). The amorphous silica slab model we previously developed ${ }^{47}$ was used to study various configurations of glycine adsorption, taking explicitly into account possible interfacial water molecules. Finally, and in order to determine the relevance of the models, first principles calculations of NMR parameters were performed by using the GIPAW method for all involved nuclei and compared with experimental data.

\section{EXPERIMENTAL DETAILS}

2.1. Material Preparation. 2.1.1. MCM-41 Sample Synthesis. Mesoporous silica MCM-41 was obtained by solubilizing cetyltrimethylammonium bromide (CTAB, 17.24 g) in $\mathrm{H}_{2} \mathrm{O}(350 \mathrm{~g})$ at $40{ }^{\circ} \mathrm{C}$ and mixing this solution with an aqueous solution of $52.5 \mathrm{~g}$ of sodium silicate $\left(27 \% \mathrm{SiO}_{2}, 10 \%\right.$ $\mathrm{NaOH})$ in $54.5 \mathrm{~g}$ of water for $10 \mathrm{~min}$. The $\mathrm{SiO}_{2} / \mathrm{CTAB} /$ $\mathrm{NaOH} / \mathrm{H}_{2} \mathrm{O}$ molar ratio was $1: 0.55: 0.25: 127$. The $\mathrm{pH}$ was then adjusted to 8.5 by adding, under stirring, $\sim 108 \mathrm{~mL}$ of $1 \mathrm{M} \mathrm{HCl}$. The mixture was heated at $90{ }^{\circ} \mathrm{C}$ for $24 \mathrm{~h}$. A solid white powder formed in the reaction mixture; it was washed with distilled water, dried at $60{ }^{\circ} \mathrm{C}$ overnight, and then heated at 540 ${ }^{\circ} \mathrm{C}$ for $8 \mathrm{~h}$ under air flux to remove the surfactant.

2.1.2. Gly Deposition on MCM-41. The calcined MCM-41 sample was loaded with glycine according to the "incipient wetness" procedure: $0.300 \mathrm{~g}$ of MCM-41 was impregnated with a small amount $(2 \mathrm{~mL})$ of $0.1 \mathrm{M}$ aqueous glycine solution, allowing the complete filling of the pore volume of MCM-41 (without formation of a bulk liquid phase). This resulted in the deposition of $0.67 \mathrm{mmol}$ Gly per gram of MCM-41, or a loading of $5.0 \mathrm{wt} \%$. The sample was then dried at $60{ }^{\circ} \mathrm{C}$ for 3.5 days. In order to increase the signal-to-noise ratio of the NMR spectra, glycine isotopically enriched in ${ }^{15} \mathrm{~N}$ and ${ }^{13} \mathrm{C}$ (the latter on the carboxyl function) was employed. This sample will be called Gly/MCM.

Nitrogen adsorption/desorption isotherms were recorded at $77 \mathrm{~K}$ with a Micromeritics ASAP2000 apparatus, after degassing under vacuum $\left(1 \times 10^{-3}\right.$ Torr $)$ at $250{ }^{\circ} \mathrm{C}$ for pure calcined MCM-41 or $40{ }^{\circ} \mathrm{C}$ for the glycine-loaded sample.

2.2. Solid-State NMR Experiments. The ${ }^{13} \mathrm{C},{ }^{15} \mathrm{~N}$ CP (Cross-Polarization) MAS experiments were recorded on a Bruker Avance 400 spectrometer $\left(9.4 \mathrm{~T}, \nu_{0}\left({ }^{1} \mathrm{H}\right)=400.78 \mathrm{MHz}\right.$, 
$\left.\nu_{0}\left({ }^{13} \mathrm{C}\right)=100.61 \mathrm{MHz}, \nu_{0}\left({ }^{15} \mathrm{~N}\right)=40.56 \mathrm{MHz}\right)$, and $2 \mathrm{D}$ HETCOR (HETeronuclear CORrelation) experiments were recorded on a Bruker Avance III 300 spectrometer $(7.0 \mathrm{~T}$, $\nu_{0}\left({ }^{1} \mathrm{H}\right)=300.29 \mathrm{MHz}, \nu_{0}\left({ }^{13} \mathrm{C}\right)=75.51 \mathrm{MHz}, \nu_{0}\left({ }^{15} \mathrm{~N}\right)=30.44$ $\left.\mathrm{MHz}, \nu_{0}\left({ }^{29} \mathrm{Si}\right)=59.66 \mathrm{MHz}\right)$. At both fields, Bruker $4 \mathrm{~mm}$ double resonance MAS probes were used, and the samples were spun at the magic angle at $14 \mathrm{kHz}$.

$2 \mathrm{D}{ }^{1} \mathrm{H}-\mathrm{X}$ HETCOR CP MAS experiments $\left(\mathrm{X}={ }^{13} \mathrm{C},{ }^{15} \mathrm{~N}\right.$, and ${ }^{29} \mathrm{Si}$ ) were recorded with ramped-amplitude cross-polarization (RAMP-CP) ${ }^{48}$ in the ${ }^{1} \mathrm{H}$ channel to transfer magnetization from ${ }^{1} \mathrm{H}$ to $\mathrm{X}$ (typically, 64 increments of $63 \mu$ s were used with 600 scans per acquisition). The ${ }^{1} \mathrm{H}$ field was ramped from 50 to $100 \%$ while the X RF field was set around $65 \mathrm{kHz}$. $\mathrm{RD}=3 \mathrm{~s}, t_{90^{\circ}}\left({ }^{1} \mathrm{H}\right)=3 \mu \mathrm{s}, \mathrm{CP}$ contact time $=1 \mathrm{~ms}$, optimized ${ }^{1} \mathrm{H}$ spinal-64 decoupling.

A single pulse ${ }^{29} \mathrm{Si}$ NMR MAS spectrum was also recorded at 7.0 T with a Bruker $7 \mathrm{~mm}$ double resonance MAS probe, spinning at $5 \mathrm{kHz}, 5.0 \mu \mathrm{s} \pi / 2$ pulses, and a recycle delay of $60 \mathrm{~s}$. Spectra deconvolutions were performed using the Dmfit software. ${ }^{49}{ }^{1} \mathrm{H},{ }^{13} \mathrm{C}$, and ${ }^{29} \mathrm{Si}$ chemical shifts were referenced to external TMS, while ${ }^{15} \mathrm{~N}$ was referenced to external $\mathrm{CH}_{3} \mathrm{NO}_{2}$.

2.3. Computational Details. 2.3.1. Ab Initio Geometrical Configurations and Molecular Dynamics Calculations. All calculations were performed using the ab initio plane-wave pseudopotential approach as implemented in the VASP code. $^{50,51}$ The Perdew-Burke-Ernzerhof (PBE) functional ${ }^{52,53}$ was chosen to perform the periodic DFT calculations with an accuracy on the overall convergence tested elsewhere. ${ }^{47,54-58}$ The valence electrons were treated explicitly and their interactions with the ionic cores are described by the Projector Augmented-Wave (PAW) method, ${ }^{59,60}$ which allows one to use a low energy cutoff equal to $400 \mathrm{eV}$ for the plane-wave basis. The integration over the Brillouin zone was performed on the $\Gamma$-point, in all calculations.

The potential energy surfaces (PESs) were systematically explored by ab initio molecular dynamics at $300 \mathrm{~K}$, starting from several configurations. The time step was set at $1.5 \mathrm{fs}$; several starting conformations were considered (but no statistic was performed on the starting conformations), and the run was stopped when an average stable conformation was reached during $500 \mathrm{fs}$ or more; we used a microcanonical ensemble in the NVE (constant number of molecules, constant volume and constant energy) approach. To avoid fluctuations due to the large time step chosen, the mass of the hydrogen atom was set to 3 . The local minima found in the PES were then optimized at $0 \mathrm{~K}$. It is noticeable that this $\mathrm{MD}$ approach allowed us to find the minima of the PES showed in the present paper, which were not intuited beforehand. Glycine was adsorbed in its zwitterionic form (ZG).

In the geometry optimizations at $0 \mathrm{~K}$, the positions of all atoms in the supercell are relaxed in the potential energy determined by the full quantum mechanical electronic structure until the total energy differences between the loops is less than $10^{-4} \mathrm{eV}$. In a second step, the DFT-D approach ${ }^{61}$ was applied as implemented in VASP, which consists in adding a semiempirical dispersion potential to the conventional Kohn-Sham DFT energy. In particular we used the DFT-D method of Grimme ${ }^{62}$ up to D2 correction.

The energies of interaction/adsorption of glycine on the surface were calculated following different reactions: First, neutral glycine (NG) was considered as the adsorbant. The adsorption energy $\Delta E_{\text {ads }}$ was calculated as follows:

$$
\Delta E_{\mathrm{ads}}=E(\mathrm{G}, \mathrm{Sil})-E(\mathrm{NG})-E(\mathrm{Sil})-n E\left(\mathrm{H}_{2} \mathrm{O}\right)
$$

where $E(\mathrm{NG}), E(\mathrm{Sil})$, and $E\left(\mathrm{H}_{2} \mathrm{O}\right)$ are the total electronic energies of $\mathrm{NG}$, silica surface, and one water molecule obtained after separate geometry optimization. $E(G, S i l)$ is the energy of the optimized (glycine + silica $+n$ water) system with glycine adsorbed on the silica surface. The number of water molecules in the models runs up to 3 .

The adsorption energy can be decomposed into interaction and deformation energies, as follows:

$$
\Delta E_{\text {ads }}=\Delta E_{\text {binding }}-\Delta E_{\text {deform-mol }}-\Delta E_{\text {deform-surface }}
$$

where $\Delta E_{\text {deform-mol }}$ of the molecule and $\Delta E_{\text {deform-surface }}$ of the surface indicates the energy required for the molecule (respectively, the surface) to adapt to the constraints induced by the surface (respectively, the molecule), and $\Delta E_{\text {binding }}$ is the energy of the bond between the surface and the molecule, in the geometries of the adsorption configuration. $\Delta E_{\mathrm{ads}}$ is negative, indicating an exothermic process, when the binding energy between the molecule and the surface is more important than the induced respective deformations.

2.3.2. Ab initio Calculations of NMR Parameters. The first principles NMR calculations were performed within KohnSham DFT using the QUANTUM-ESPRESSO software (available online). ${ }^{63}$ The PBE generalized gradient approximation ${ }^{52,53}$ was used. and the valence electrons were described by norm conserving pseudopotentials ${ }^{64}$ in the KleinmanBylander ${ }^{65}$ form. The core definition for $\mathrm{O}, \mathrm{C}$, and $\mathrm{N}$ is $1 \mathrm{~s}^{2}$ and $1 \mathrm{~s}^{2} 2 \mathrm{~s}^{2} 2 \mathrm{p}^{6}$ for Si. The core radii are 1.2 au for $\mathrm{H}, 1.5$ au for $\mathrm{O}$, $1.6 \mathrm{au}$ for $\mathrm{C}, 1.45 \mathrm{au}$ for $\mathrm{N}$, and $2.0 \mathrm{au}$ for $\mathrm{Si}$. The wave functions were expanded on a plane wave basis set with a kinetic energy cutoff of $1088 \mathrm{eV}$. The integral over the first Brillouin zone was performed using a Monkhorst-Pack $1 \times 1 \times$ 1 k-point grid for the charge density and chemical shift tensor calculation. The shielding tensor is computed using the GIPAW $^{40}$ approach which permits the reproduction of the results of a fully converged all-electron calculation. The isotropic chemical shift $\delta_{\text {iso }}$ is defined as $\delta_{\text {iso }}=-\left[\sigma-\sigma^{\text {ref }}\right]$, where $\sigma$ is the isotropic shielding and $\sigma^{\text {ref }}$ is the isotropic shielding of the same nucleus in a reference system as previously described. ${ }^{66,67}$

2.3.3. Description of the Model. The adsorption of glycine was studied using a silica model structure described and characterized in a previous work. ${ }^{47}$ In summary, the model consists of a $\mathrm{Si}_{27} \mathrm{O}_{54}$ slab hydrated with $13 \mathrm{H}_{2} \mathrm{O}$ molecules. The silanol density at the surface is $5.8 \mathrm{~nm}^{-2}$, and unit cell dimensions are $12.77 \times 17.64 \times 25.17 \AA^{3}$. The slab has a density of approximately $1.7 \mathrm{~g} / \mathrm{cm}^{3}$. The number of $\mathrm{Si}$ atoms belonging to tetrahedra exposed on the surface is approximately $8 \mathrm{~nm}^{-2}$. The same slab has been used in studies in which the model was used to describe a catalyst support. ${ }^{68-71}$ Despite the fact that the global silanol density is higher than the one usually reported for MCM-41, ${ }^{72}$ locally, the different expected types (terminal and geminal) are present on the model surface, enabling, thus, a correct, local, description of the interaction sites.

\section{RESULTS AND DISCUSSION}

3.1. Surface Area and Porosity. Nitrogen adsorption/ desorption isotherms of the calcined MCM-41 and the glycineloaded sample (see the Supporting Information for details, Figure $\mathrm{S} 1$ and Table S1) provided specific surface areas, evaluated by BET calculations, ${ }^{73}$ of 1060 and $830 \mathrm{~m}^{2} \cdot \mathrm{g}^{-1}$, 
respectively. Both the mean pore diameter estimated by the $\mathrm{BJH}$ method $^{74}$ and the mesoporous volume decrease after loading, in line with the successful incorporation of glycine in the mesopores of MCM-41.

3.2. Solid-State NMR Investigation. In the carboxylate region, the ${ }^{13} \mathrm{C} \mathrm{CP}$ MAS spectrum of glycine encapsulated in mesoporous silica (Figure 1) exhibits a sharp signal at 176.4 ppm and a distribution of broader ones ranging from 168 to $175 \mathrm{ppm}$, with one maximum at $173.6 \mathrm{ppm}$. Similar results have already been observed for glycine adsorbed on nonporous silica nanoparticules (Aerosil 380): ${ }^{8,75}$ the sharp line was assigned to bulk $\alpha$-glycine ${ }^{76}\left({ }^{13} \mathrm{C}\right.$ CP MAS spectra of the $\alpha, \beta$ and $\gamma$ polymorphs of glycine are presented in Figure 1), while the broader line could correspond to a population of glycine molecules interacting with silica surface groups (most likely silanols) and/or adsorbed water molecules. $\mathrm{A}{ }^{13} \mathrm{C}$ single-pulse (SP) MAS NMR spectrum of the sample was also recorded (Supporting Information Figure S2): this experiment corresponds to direct ${ }^{13} \mathrm{C}$ detection, without $\mathrm{CP}$ from ${ }^{1} \mathrm{H}$ to ${ }^{13} \mathrm{C}$. The signal assigned to crystalline glycine is very similar in the two spectra (SP and CP), but important differences are visible in the 168-175 ppm range. Instead of a distribution of broad signals in the CP spectrum, only one sharper signal at 173.5 ppm is present in the SP spectrum, with no clear sign of any of the broader components present in the $\mathrm{CP}$ spectrum. This suggests the existence of two populations of glycine molecules: one mobile enough not to be detected by $\mathrm{CP}$ due to an efficient averaging of the ${ }^{1} \mathrm{H}-{ }^{13} \mathrm{C}$ dipolar interactions, and one more rigid detected by $\mathrm{CP}$, a priori corresponding to the molecules strongly interacting with the surface (apart from crystalline forms of glycine). Similar observations were already reported for encapsulated molecules in MCM-41. ${ }^{6,77}$ The population detected by $\mathrm{CP}$ is thus the one of interest for the present study.

A two-dimensional ${ }^{1} \mathrm{H}-{ }^{13} \mathrm{C}$ HETCOR CP MAS NMR experiment was recorded in order to discriminate between ${ }^{1} \mathrm{H}$ sites according to their proximities to the different carbon atoms (Figure 2a). The ${ }^{13} \mathrm{C}$ signal at $176.4 \mathrm{ppm}$ assigned to bulk $\alpha$-glycine clearly shows two cross peaks with proton signals at $3.2 \mathrm{ppm}$ and $8.4 \mathrm{ppm}$ corresponding to the methylene group bonded to the carboxylate and to the ammonium group in interaction with the carboxylate of a neighboring molecule through $\mathrm{NH}-\mathrm{OOC}$ hydrogen bonds in the bulk state. Two cross peaks centered at 4.3 and $7.2 \mathrm{ppm}$ are observed for the ${ }^{13} \mathrm{C}$ signal at $173.6 \mathrm{ppm}$. The first ${ }^{1} \mathrm{H}$ chemical shift is possibly due to the superposition of methylene and water signals while the second is consistent with an ammonium group or with silanols/water in interaction with the carboxylate. Finally, the larger ${ }^{13} \mathrm{C}$ signal centered at $171.5 \mathrm{ppm}$ only correlates with a proton signal at $4.7 \mathrm{ppm}$. The latter is usually assigned to the protons of silanols in fast exchange with adsorbed water on imperfectly dehydrated silica, be it mesoporous or nonporous. ${ }^{78}$ The conventional ${ }^{1} \mathrm{H}$ MAS spectrum (Supporting Information Figure S3) shows indeed a predominant large signal centered at $5 \mathrm{ppm}$ characteristic of the presence of water.

The ${ }^{15} \mathrm{~N}$ CP MAS spectrum of Gly/MCM (Figure 3) shows a narrow signal at $-346.6 \mathrm{ppm}$ corresponding to the chemical shift of ammonium groups in $\alpha$-glycine and a second component centered at $-348.5 \mathrm{ppm}$ most probably corresponding to the glycine in interaction with the surface. A twodimensional ${ }^{1} \mathrm{H}-{ }^{15} \mathrm{~N}$ HETCOR CP MAS NMR experiment was then recorded to identify ${ }^{1} \mathrm{H}$ chemical shifts of the ammonium groups of these two types of glycine (Figure $2 b$ ). Consistently with the ${ }^{13} \mathrm{C}$ results, the ${ }^{15} \mathrm{~N}$ signal at $-346.6 \mathrm{ppm}$ shows a proton cross peak at $8.6 \mathrm{ppm}$, assigned to the ammonium protons of bulk glycine ${ }^{76}$ while the ${ }^{15} \mathrm{~N}$ peak at
$-346.6 \mathrm{ppm}$ is correlated to a ${ }^{1} \mathrm{H}$ signal at $6.4 \mathrm{ppm}$ possibly corresponding to $-\mathrm{NH}$ protons involved in a $\mathrm{H}$-bond network with the silica surface. The weak cross peak at $3.7 \mathrm{ppm}$ can be assigned to the protons of the $\mathrm{CH}_{2}$ linked to the ammonium.

Finally, the 2D ${ }^{1} \mathrm{H}-{ }^{29} \mathrm{Si}$ HETCOR CP MAS NMR spectrum of the sample (Figure 2c) confirms that the protons with chemical shift values centered at about $5 \mathrm{ppm}$ are strongly correlated with surface silicon atoms (they were assigned above to silanols in fast exchange with water). Overall, the HETCOR results are very similar to those published by Ben Shir et al. for Gly/SBA-15 in the "intermediate" hydration state. ${ }^{8}$

3.3. Theoretical Investigations of Adsorption Geometries. Several combinations of $\mathrm{H}$-bonds between glycine and the surface were investigated. We refer to our previous paper for the description of the model silica surface, ${ }^{47}$ which exhibits vicinal and geminal silanols and their combinations into silanol nests. Using this model, we explore the possibility of cooperative $\mathrm{H}$-bond formation between glycine, silanols, and water.

First, glycine interaction with two types of surface sites (vicinal, and silanol nest containing geminal silanol groups) was investigated. Then water was coadsorbed with glycine. The adsorption energies were calculated using eq 1 .

Zwitterionic glycine (ZG) adsorption through one or two Hbonds with the silanols results in spontaneous neutralization to neutral glycine $(\mathrm{NG})$, yielding adsorption energies of -55 and $-62 \mathrm{~kJ} / \mathrm{mol}$ (Figure $4 \mathrm{a}$ and $\mathrm{b}$ ). It must be underlined that, in this configuration, the surface does not "solvate" the glycine molecule, in the sense that the interaction is not sufficient to stabilize the zwitterionic form with respect to the neutral form as happens, for example, in water, in conformity with previously calculated results. ${ }^{9,11}$ When glycine is allowed to make three $\mathrm{H}$ bonds to the surface (Figure 4c,d), the ZG form is stabilized, although the energy of adsorption $(-64$ and $-69 \mathrm{~kJ} / \mathrm{mol})$ is not significantly more negative than in the previous case. The rather weak interaction of glycine with vicinal silanols was confirmed with $\mathrm{MD}$ runs at $300 \mathrm{~K}$. For all the previous structures, the glycine molecule spontaneously desorbs from the surface in its neutral form.

The same trend of neutralization was observed on the geminal silanol pair with glycine forming two $\mathrm{H}$-bonds, with an energy of adsorption of $-64 \mathrm{~kJ} / \mathrm{mol}$ (Figure $5 \mathrm{a}$ ). The geminal pair behaves similarly to the vicinal silanols, in agreement with previous results regarding water adsorption on silanols. ${ }^{47}$ These results suggest that geminal silanols do not exhibit an increased acidity as compared to vicinal ones. Then, a minimum in the potential energy surface (glycine/silanol nest) was searched by means of molecular dynamics followed by geometry optimization. Figure $5 \mathrm{~b}$ shows the most stable configuration obtained, with three H-bonds formed. The COO moiety is two times $\mathrm{H}$-bond receiver from the geminal pair; in addition, the $\mathrm{NH}_{3}$ moiety is one time $\mathrm{H}$-bond donor to a vicinal silanol. Subsequently, the ZG form was stabilized and an adsorption energy of $-111 \mathrm{~kJ} / \mathrm{mol}$ was calculated, exhibiting a more exothermic adsorption than on vicinal silanols.

The most stable configuration in dehydrated conditions, (Figure $5 b$ ), shows the glycine molecule parallel to the surface with three $\mathrm{H}$-bonds, an additional bond being formed between the $\mathrm{NH}_{3}{ }^{+}$moiety and a vicinal silanol. Moreover, a $\mathrm{Si}-\mathrm{O}-\mathrm{H}-$ $\mathrm{O}-\mathrm{C}-\mathrm{O}-\mathrm{H}-\mathrm{O}-\mathrm{Si}-\mathrm{O}$ cycle is formed. The energy of glycine adsorption is now $-111 \mathrm{~kJ} / \mathrm{mol}(148 \mathrm{~kJ} / \mathrm{mol} \mathrm{vdW}$ corrected). This energy of adsorption is much more exothermic than that calculated in other configurations. To better understand this result, the adsorption energy was decomposed into interaction and deformation energies as in eq 2 . 
Table 1 reports those energies for the most stable configurations obtained for glycine adsorbed on vicinal silanols and on a silanol nest. The H-bond network of silica has slightly changed in the presence of adsorbed glycine, with reorientations of $\mathrm{H}$-bonds. The average deformation energy of the silica model is rather weak $(38.5 \pm 1 \mathrm{~kJ} / \mathrm{mol})$, which is not surprising since this solid is known to be very flexible. The average deformation energy of the glycine molecule is $68 \pm 5 \mathrm{~kJ} / \mathrm{mol}$. Thus, deformation energies do not vary significantly between both configurations, and they cannot explain the differences in adsorption energies. It should be noted that the energy trends in Table 1 are not altered after inclusion of dispersion forces in a same set of model systems (i.e., the same number of atoms), as all energies are uniformly increased by about $30-50 \mathrm{~kJ} / \mathrm{mol}$ depending on the degree of hydration. This correction is similar for both types of silanols, i.e. geminal and terminal. The most favorable adsorption configuration is found on geminal silanols, confirming our former result. ${ }^{10}$

We performed the following additional calculations: for the most stable configurations obtained in each case (vicinal silanols/silanol nest), the atoms of glycine and the oxygens surrounding it were kept frozen. The other atoms of the structure were eliminated. Oxygen atoms were saturated with $\mathrm{H}$ atoms to form water molecules; those $\mathrm{H}$ atoms were optimized, converging into the structures shown in Figure 6. It was noticed that the interaction of glycine with the water clusters increases with the size and $\mathrm{H}$-bond connectivity in the water cluster, from -53 to $-114 \mathrm{~kJ} / \mathrm{mol}$. Indeed, water molecules help to screen the glycine dipole, and thus to stabilize the negative and positive charges of zwitterionic glycine. In other words, the high local silanol density, rather than the nature of the silanols, explains the increased (i.e., more negative) adsorption energy of glycine on silica. Such an increased reactivity of silanol nests was observed on other models (molecular and peri- odic). ${ }^{57,68-71,79,80}$

In order to obtain a benchmark for the experimental NMR analysis showing the presence of a non-negligible amount of water, water molecules bridging glycine and the surface were considered, to calculate the corresponding NMR shifts (vide infra). This was achieved by adding three water molecules to the model system. Figure 7 shows the two most stable configurations obtained after $\mathrm{MD}$ followed by geometry optimization of the local minima. In both the silanol nest and vicinal silanol cases, the water molecules bridging the $\mathrm{COO}^{-}$ moiety to the silanols are $\mathrm{H}$-bond donors to $\mathrm{COO}^{-}$and $\mathrm{H}_{-}$ bond acceptors from silanols. In contrast, water $\mathrm{H}$-bond acceptors from $\mathrm{NH}_{3}{ }^{+}$are $\mathrm{H}$-bond donor to silanols/siloxane oxygens. The energies of glycine+water coadsorption are -253 $(-305)$ and $-193(-233) \mathrm{kJ} / \mathrm{mol}$ for silanol nest and vicinal silanols respectively, at the DFT (DFT-D) level. Again, we notice that the inclusion of van der Waals forces enhances the adsorption energy, by about $45 \mathrm{~kJ} / \mathrm{mol}$.

When only one water molecule is added to the model system as is the case in the last configuration, the glycine is found to interact directly with silanol groups through the carboxylate group whereas the ammonium group interacts via the water molecule. The adsorption energy obtained is $-168(-219) \mathrm{kJ} /$ mol (See Figure 8). We notice that the addition of one water molecule to the $\mathrm{NH}_{3}{ }^{+}$end is exothermic by $-72 \mathrm{~kJ} / \mathrm{mol}$. Adding water molecules at the $\mathrm{COO}^{-}$end is exothermic by $-43 \mathrm{~kJ} / \mathrm{mol}$ per water molecule. Those values fall to -60 (one water molecule) and -31 (two more water molecules) $\mathrm{kJ} / \mathrm{mol}$, respectively, considering the ZPE differences between the gas phase water and water adsorbed on the surface. ${ }^{81}$ It seems thus that the addition of one water molecule at the ammonium end is more exothermic than at the carboxylate end. This may be due to the better screening of the charge of the proton in $\mathrm{NH}_{3}{ }^{+}$ by an additional water molecule. Such a trend was already

Table 1. Adsorption Energies of Glycine (G) on Different Types of Silanols and Interaction Energy of Glycine with Water Clusters of Identical Geometry, Calculated at the DFT (DFT-D) Levels Following eqs 1 and $2^{a}$

\begin{tabular}{|c|c|c|c|c|c|c|c|}
\hline & & \multicolumn{4}{|c|}{ vicinal } & \multicolumn{2}{|c|}{ geminal } \\
\hline & & NG & NG & ZG & $\mathrm{ZG}$ & NG & ZG \\
\hline \multirow[t]{5}{*}{ dry } & Figure & $4 a$ & $4 b$ & $4 c$ & $4 d$ & $5 a$ & $5 b$ \\
\hline & \# H-Bonds & 1 & 2 & 3 & 3 & 2 & 3 \\
\hline & $\Delta E_{\text {ads }}$ & -55 & -62 & -64 & -69 & -64 & -111 \\
\hline & & & & $(-96)$ & & & $(-148)$ \\
\hline & & & & & & & $-142^{10}$ \\
\hline \multirow[t]{4}{*}{1 water molecule } & Figure & & & & & & 8 \\
\hline & \# H-Bonds & & & & & & $3+2$ water \\
\hline & $\Delta E_{\text {ads }}$ & & & & & & -168 \\
\hline & & & & & & & $(-219)$ \\
\hline \multirow[t]{4}{*}{3 water molecules } & Figure & & & & & $7 a$ & $7 \mathrm{~b}$ \\
\hline & \# H-Bonds & & & & & 8 & 8 \\
\hline & $\Delta E_{\mathrm{ads}}$ & & & & & -193 & -253 \\
\hline & & & & & & $(-233)$ & $(-304)$ \\
\hline
\end{tabular}

${ }^{a}$ Values in $\mathrm{kJ} / \mathrm{mol}$. 
observed in a previous work. ${ }^{10}$ Moreover, it was recently shown by molecular dynamics studies that the $\mathrm{NH}_{3}{ }^{+}$moiety does not interact directly with the surface silanols, whereas the carboxylate end does, at the silica-water interface. ${ }^{37,82}$

The results present a first order approximation for systems considering a real silica-water interface on which a molecular thermodynamical approach can be conducted in order to estimate the number of water molecules coadsorbed with glycine. ${ }^{83}$ This can be achieved by calculating free energies of adsorption from the liquid phase with an a posteriori treatment based on atomistic thermodynamics. In this approach chemical potentials of the reactants and products in the liquid phase are estimated. ${ }^{81}$

The free energies of glycine and water coadsorption are estimated to -16 and $+12 \mathrm{~kJ} / \mathrm{mol}$ in the case of addition of one water molecule at the $\mathrm{NH}_{3}^{+}$end, and addition of two water molecules at the carboxylate end, respectively. To summarize, the interaction of glycine with amorphous silica is predicted to occur via its ammonium group through one water molecule, whereas a direct interaction via the carboxylate group with the surface is favored.

It is interesting to notice that Ben Shir et al. ${ }^{8}$ concluded from NMR experiments that the carboxylate group is mobile and does not interact with the silica surface, while the ammonium group is tightly bond via three hydrogen bonds to the silanols of the silica surface. They described their rate of hydration to be intermediate, whereas in relatively dry conditions the carboxylate group is energetically predicted to be adsorbed on the surface. The theoretical model presented in this work, aimed to describe low hydration rates (microsolvation), might not be hydrated enough to represent the experimental adsorption conditions. The presence of water around the glycine molecule and on the silica surface might generate entropically favored configurations, ruling over the enthalpically favored ones, a situation already proposed in the interaction of a phospholipid on a silica surface. ${ }^{44}$

The present results point out that (i) geminal silanols "per se" do not have an increased reactivity in comparison to vicinal silanols; (ii) instead they participate in creating a "silanol nest", a local region of high silanol density, which exhibits an increased reactivity toward glycine; (iii) glycine adsorption on a "silanol nest" is significantly more exothermic, than on vicinal silanols; (iv) this result is valid also when water is coadsorbed with glycine, and (v) water coadsorbs preferentially at the $\mathrm{NH}_{3}{ }^{+}$ moiety of glycine, in agreement with previous studies. ${ }^{10,37}$

3.4. NMR Calculations. Calculations of NMR parameters were performed on four configurations of glycine adsorption on the surface (Figure 9): (i) Glycine carboxylate forming two $\mathrm{H}$ bonds with two geminal silanols (config I, Figure 5b); (ii) glycine carboxylate forming two H-bonds with two vicinal silanols (config II, Figure 4c); (iii) glycine carboxylate forming two H-bonds with two geminal silanols via two interfacial water molecules (config III, Figure 7a); (iv) glycine carboxylate forming two $\mathrm{H}$-bonds with two vicinal silanols via two interfacial water molecules (config IV, Figure 7b).

The corresponding calculated ${ }^{1} \mathrm{H},{ }^{13} \mathrm{C}$, and ${ }^{15} \mathrm{~N}$ NMR chemical shift values are summarized in Table 2.

${ }^{13} \mathrm{C}$ and ${ }^{15} \mathrm{~N}$ chemical shift values calculated for the different adsorption configurations (shown in Figure 9) were positioned on a theoretical two-dimensional map, in regard with the experimental ${ }^{13} \mathrm{C}$ and ${ }^{15} \mathrm{~N}$ spectra (Figure 10). It must be underlined that this figure is not an experimental $2 \mathrm{D}$ NMR map. The calculated chemical shifts of the three polymorphs of glycine are also shown as references. It appears that all adsorption configurations yield NMR parameters consistent with the experimental signals previously assigned to glycine in interaction with the silica surface, and separate from the parameters of bulk glycine (at least along the ${ }^{13} \mathrm{C}$ chemical shift dimension), giving confidence in the used methodology. Additional data are necessary to determine whether one of the various models is more relevant than the others from the NMR point of view. Therefore, attention was then focused on the calculated ${ }^{1} \mathrm{H}$ chemical shifts of ammonium protons of glycine and on silanol/water protons interacting with glycine (Figure 11). Apart from configuration III, the $-\mathrm{NH}_{3}{ }^{+}$protons show chemical shifts smaller than in glycine polymorphs ${ }^{80}(8.0$ ppm for $\alpha$ - and $\gamma$-glycine, and 8.9 ppm for $\beta$-glycine), in good agreement with the experimental value of $6.4 \mathrm{ppm}$ extracted from the ${ }^{1} \mathrm{H}-{ }^{15} \mathrm{~N}$ HETCOR CP MAS NMR experiment. For configurations I and III, the $\delta_{\text {iso }}\left({ }^{1} \mathrm{H}\right)$ of silanols $\mathrm{H}$-bonded to the carboxyl oxygens of glycine are very high (between 9.4 and $9.7 \mathrm{ppm}$ ) which is most probably related to very short $\mathrm{O} \underline{\mathrm{H}}-\underline{\mathrm{O}}$ distances (between 1.56 and $1.66 \AA$ ). Indeed, a correlation between proton chemical shift of silanols and the H-bond network has been reported previously. ${ }^{47}$ For the vicinal configurations, $\delta_{\text {iso }}\left({ }^{1} \mathrm{H}\right)$ of silanols or water molecules $\mathrm{H}$ bonded to the COO- group are smaller (between 5.1 and 6.5 $\mathrm{ppm})$ and the corresponding $\mathrm{O} \underline{\mathrm{H}}-\underline{\mathrm{O}}$ distances are longer (between 1.70 and $1.74 \AA$ ). The latter values are in better agreement with the experimental values extracted from the ${ }^{1} \mathrm{H}-{ }^{13} \mathrm{C}$ and ${ }^{1} \mathrm{H}-{ }^{29} \mathrm{Si}$ HETCOR CP MAS NMR experiment.

All in all, the best agreement between experimental and calculated NMR data is obtained for configurations II and IV,

Table 2. Comparison between Experimental and Calculated NMR ${ }^{1} \mathrm{H},{ }^{13} \mathrm{C}$ and ${ }^{15} \mathrm{~N}$ Chemical Shift Values for Various Adsorption Configurations of Glycine on the Silica Surface

\begin{tabular}{|c|c|c|c|c|c|}
\hline \multirow[b]{2}{*}{ glycine site } & \multicolumn{5}{|c|}{$\delta_{\text {iso }}(\mathrm{ppm})$} \\
\hline & $\exp$ & Config I (5b) & Config II (4c) & Config III (7a) & Config IV (7b) \\
\hline $\mathrm{COO}^{-}$ & $173.6-171.5$ & 173.2 & 170.9 & 170.9 & 169.2 \\
\hline $\mathrm{NH}_{3}$ & -348.5 & -349.3 & -348.0 & -349.2 & -348.5 \\
\hline $\mathrm{NH}_{3}$ & 6.4 & 7.0 & 7.3 & 8.1 & 7.5 \\
\hline$-\mathrm{OH}\left(\mathrm{SiOH}\right.$ or $\left.\mathrm{H}_{2} \mathrm{O}\right)$ interacting with $\mathrm{COO}^{-}$ & $4.2-5.0$ & $9.5 ; 9.7$ & $5.8 ; 6.4$ & $9.4 ; 9.6$ & $5.7 ; 6.9$ \\
\hline
\end{tabular}


corresponding to the adsorption on vicinal silanols: this is interesting because these are much more abundant than geminal sites according to the ${ }^{29} \mathrm{Si}$ MAS NMR spectrum of the sample showing $2.7 \%$ au $\mathrm{Q}_{2}$ (geminal silanols), $23.9 \%$ of $\mathrm{Q}_{3}$ (vicinal silanols), and $71.4 \%$ of $\mathrm{Q}_{4}$ (fully condensed $\mathrm{Si}(\mathrm{OSi})_{4}$ ) sites (Supporting Information Figure S4). Nonetheless, considering the accuracy of experimental results, all calculated NMR shifts fall within the experimental range suggesting that a distribution of adsorption configurations cannot be excluded.

\section{CONCLUSIONS}

DFT-D calculations have been performed on a model amorphous silica surface, in order to help interpreting experimental NMR data. Several typical configurations were considered, where glycine was adsorbed on vicinal or geminal silanols, without and with water coadsorption. ${ }^{13} \mathrm{C}$ and ${ }^{15} \mathrm{~N}$ NMR signal corresponding to the relatively rigid glycine molecules interacting with the silica surface could be clearly identified by combining CP experiments and NMR calculations on the models. Moreover, it appears that the best site for adsorption configuration was the silanol nest, and that water coadsorption was favored, especially concerning the ammonium entity. Calculated NMR shifts fall into the experimental range with a slightly better agreement for adsorption configurations on vicinal silanols, which are present in majority on this silica. However, contributions from zones of high local density of silanols cannot be excluded.

Finally, we notice that our representative silica model exposes sites of very different reactivity, and is thus useful to explore different possibilities of adsorption, at low computational cost. Comparison with experimental data may be done by extracting data on particular sites that are known to be present on real surfaces. Obviously, our results are more indicative of tendencies than precise assignments. In particular, the electronic energy of the system is not the only criteria to discriminate between different adsorption scenarios. One might describe a very stable site and adsorption configuration on the basis of its energy but, due to its small probability of presence on the surface (as for example geminal silanols in MCM-41 sample), it may not be the most representative adsorption situation. The presence of the surface sites is dependent on the synthesis protocol of the silica material. Another unknown condition of adsorption is the accessibility of the surface site for the glycine molecule. The adsorbent may be blocked by steric hindrance. The role of the solvent is also a parameter to be considered, and will be the subject of future works.

\section{ASSOCIATED CONTENT}

\section{S Supporting Information}

Table containing porosity characteristics for loaded and unloaded MCM-41; additonal figures showing nitrogen adsorption-desorption isotherms and NMR spectra of MCM-41 samples. This material is available free of charge via the Internet at http://pubs.acs.org.

\section{AUTHOR INFORMATION}

\section{Corresponding Author}

*E-mail: christel.gervais_stary@upmc.fr (C.G.); frederik. tielens@upmc.fr (F.T.).

\section{Notes}

The authors declare no competing financial interest.

\section{ACKNOWLEDGMENTS}

This work was performed using HPC resources from GENCI[CCRT/CINES/IDRIS] (Grant 2012-[x2012082022]) and the CCRE of Université Pierre et Marie Curie. N.F. benefitted from a Ph.D. grant from the CNano program of the Ile-de-France region. The "Bonus Qualite Recherche" (BQR) 2008 program of Université Pierre et Marie Curie is gratefully acknowledged for financing the purchasing of the isotopically enriched molecules.

\section{REFERENCES}

(1) Cauvel, A.; Brunel, D.; DiRenzo, F.; Garrone, E.; Fubini, B. Hydrophobic and Hydrophilic Behavior of Micelle-Templated Mesoporous Silica. Langmuir 1997, 13, 2773-2778.

(2) Ozin, G. A.; Chomski, E.; Khushalani, D.; MacLachlan, M. J. Mesochemistry. Curr. Opin. Colloid Interface Sci. 1998, 3, 181-193.

(3) Vallee, A.; Humblot, V.; Pradier, C. M. Peptide Interactions with Metal and Oxide Surfaces. Acc. Chem. Res. 2010, 43, 1297-1306.

(4) Lambert, J.-F. Adsorption and Polymerization of Amino Acids on Mineral Surfaces: A Review. Origins Life Evol. Biospheres 2008, 38, $211-242$.

(5) Rimola, A.; Corno, M.; Garza, J.; Ugliengo, P. Ab Initio Modelling of Protein-Biomaterial Interactions: Influence of Amino Acid Polar Side Chains on Adsorption at Hydroxyapatite Surfaces. Philos. Trans. R. Soc., A 2012, 370, 1478-1498.

(6) Bonhomme, C.; Coelho, C.; Baccile, N.; Gervais, C.; Azais, T.; Babonneau, F. Advanced Solid State NMR Techniques for the Characterization of Sol-Gel-Derived Materials. Acc. Chem. Res. 2007, 40, 738-746.

(7) Ben Shir, I.; Kababya, S.; Amitay-Rosen, T.; Balazs, Y. S.; Schmidt, A. Molecular Level Characterization of the Inorganic- 
Bioorganic Interface by Solid State NMR: Alanine on a Silica Surface, a Case Study. J. Phys. Chem. B 2010, 114, 5989-5996.

(8) Ben Shir, I.; Kababya, S.; Schmidt, A. Binding Specificity of Amino Acids to Amorphous Silica Surfaces: Solid-State NMR of Glycine on SBA-15. J. Phys. Chem. C 2012, 116, 9691-9702.

(9) Costa, D.; Lomenech, C.; Meng, M.; Stievano, L.; Lambert, J.-F. Microsolvation of Glycine by Silanol Ligands: A DFT Study. J. Mol. Struct.: THEOCHEM 2007, 806, 253-259.

(10) Costa, D.; Tougerti, A.; Tielens, F.; Gervais, C.; Stievano, L.; Lambert, J. F. DFT Study of the Adsorption of Microsolvated Glycine on a Hydrophilic Amorphous Silica Surface. Phys. Chem. Chem. Phys. 2008, 10, 6360-6368.

(11) Lomenech, C.; Bery, G.; Costa, D.; Stievano, L.; Lambert, J. F. Theoretical and Experimental Study of the Adsorption of Neutral Glycine on Silica from the Gas Phase. ChemPhysChem 2005, 6, 10611070.

(12) Rimola, A.; Sodupe, M.; Tosoni, S.; Civalleri, B.; Ugliengo, P. Interaction of Glycine with Isolated Hydroxyl Groups at the Silica Surface: First Principles B3LYP Periodic Simulation. Langmuir 2006, $22,6593-6604$.

(13) Rimola, A.; Sodupe, M.; Ugliengo, P. Affinity Scale for the Interaction of Amino Acids with Silica Surfaces. J. Phys. Chem. C 2009, 113, 5741-5750.

(14) Arrouvel, C.; Diawara, B.; Costa, D.; Marcus, P. DFT Periodic Study of the Adsorption of Glycine on the Anhydrous and Hydroxylated (0001) Surfaces of Alpha-Alumina. J. Phys. Chem. C 2007, 111, 18164-18173.

(15) Irrera, S.; Costa, D.; Mucus, P. DFT Periodic Study of Adsorption of Glycine on the (0001) Surface of Zinc Terminated Zno. J. Mol. Struct.: THEOCHEM 2009, 903, 49-58.

(16) Irrera, S.; Costa, D.; Ogle, K.; Marcus, P. Molecular Modelling by DFT of 1,2-Diaminoethane Adsorbed on the $\mathrm{Zn}$-Terminated and O-Terminated, Anhydrous and Hydroxylated Zno (0001) Surface. Superlattices Microstruct. 2009, 46, 19-24.

(17) Costa, D.; Garrain, P. A.; Diawara, B.; Marcus, P. BiomoleculeBiomaterial Interaction: A DFT-D Study of Glycine Adsorption and Self-Assembly on Hydroxylated Cr2o3 Surfaces. Langmuir 2011, 27, 2747-2760.

(18) Garrain, P. A.; Costa, D.; Marcus, P. Biomaterial-Biomolecule Interaction: DFT-D Study of Glycine Adsorption on Cr2o3. J. Phys. Chem. C 2011, 115, 719-727.

(19) Ojamae, L.; Aulin, C.; Pedersen, H.; Kall, P. O. Ir and QuantumChemical Studies of Carboxylic Acid and Glycine Adsorption on Rutile TIO2 Nanoparticles. J. Colloid Interface Sci. 2006, 296, 71-78. (20) Tonner, R. Adsorption of Proline and Glycine on the TIO2(110) Surface: A Density Functional Theory Study. ChemPhysChem 2010, 11, 1053-1061.

(21) Guo, Y. N.; Lu, X.; Zhang, H. P.; Weng, J.; Watari, F.; Leng, Y. DFT Study of the Adsorption of Aspartic Acid on Pure, N-Doped, and Ca-Doped Rutile (110) Surfaces. J. Phys. Chem. C 2011, 115, 1857218581.

(22) Koppen, S.; Langel, W. Simulation of Adhesion Forces and Energies of Peptides on Titanium Dioxide Surfaces. Langmuir 2010, $26,15248-15256$.

(23) Langel, W.; Menken, L. Simulation of the Interface between Titanium Oxide and Amino Acids in Solution by First Principles Md. Surf. Sci. 2003, 538, 1-9.

(24) Fleming, G. J.; Idriss, H. Probing the Reaction Pathways of DlProline on TIO2(001) Single Crystal Surfaces. Langmuir 2004, 20, $7540-7546$.

(25) Szieberth, D.; Ferrari, A. M.; Dong, X. Adsorption of Glycine on the Anatase (101) Surface: An Ab Initio Study. Phys. Chem. Chem. Phys. 2010, 12, 11033-11040.

(26) Almora-Barrios, N.; Austen, K. F.; de Leeuw, N. H. Density Functional Theory Study of the Binding of Glycine, Proline, and Hydroxyproline to the Hydroxyapatite (0001) and (01(1)over-Bar0) Surfaces. Langmuir 2009, 25, 5018-5025.
(27) Almora-Barrios, N.; de Leeuw, N. H. A Density Functional Theory Study of the Interaction of Collagen Peptides with Hydroxyapatite Surfaces. Langmuir 2010, 26, 14535-14542.

(28) Rimola, A.; Sakhno, Y.; Bertinetti, L.; Lelli, M.; Martra, G.; Ugliengo, P. Toward a Surface Science Model for Biology: Glycine Adsorption on Nanohydroxyapatite with Well-Defined Surfaces. J. Phys. Chem. Lett. 2011, 2, 1390-1394.

(29) Rimola, A.; Aschi, M.; Orlando, R.; Ugliengo, P. Does Adsorption at Hydroxyapatite Surfaces Induce Peptide Folding? Insights from Large-Scale B3LYP Calculations. J. Am. Chem. Soc. 2012, 134, 10899-10910.

(30) Boehme, C.; Marx, D. Glycine on a Wet Pyrite Surface at Extreme Conditions. J. Am. Chem. Soc. 2003, 125, 13362-13363.

(31) Nair, N. N.; Schreiner, E.; Marx, D. Glycine at the Pyrite-Water Interface: The Role of Surface Defects. J. Am. Chem. Soc. 2006, 128, 13815-13826.

(32) Schreiner, E.; Nair, N. N.; Wittekindt, C.; Marx, D. Peptide Synthesis in Aqueous Environments: The Role of Extreme Conditions and Pyrite Mineral Surfaces on Formation and Hydrolysis of Peptides. J. Am. Chem. Soc. 2011, 133, 8216-8226.

(33) Pollet, R.; Boehme, C.; Marx, D. Ab Initio Simulations of Desorption and Reactivity of Glycine at a Water-Pyrite Interface at "Iron-Sulfur World" Prebiotic Conditions. Origins Life Evol. Biospheres 2006, 36, 363-379.

(34) Li, C.; Monti, S.; Carravetta, V. Journey toward the Surface: How Glycine Adsorbs on Titania in Water Solution. J. Phys. Chem. C 2012, 116, 18318-18326.

(35) Motta, A.; Gaigeot, M. P.; Costa, D. Aimd Evidence of Inner Sphere Adsorption of Glycine on a Stepped (101) Boehmite AlOOH Surface. J. Phys. Chem. C 2012, 116, 23418-23427.

(36) Nonella, M.; Seeger, S. Investigating Alanine-Silica Interaction by Means of First-Principles Molecular-Dynamics Simulations. ChemPhysChem 2008, 9, 414-421.

(37) Zhao, Y. L.; Koppen, S.; Frauenheim, T. An SCC-DFTB/MD Study of the Adsorption of Zwitterionic Glycine on a Geminal Hydroxylated Silica Surface in an Explicit Water Environment. J. Phys. Chem. C 2011, 115, 9615-9621.

(38) Wright, L. B.; Walsh, T. R. J. Chem. Phys. 2012, 137, 224702.

(39) Rimola, A.; Civalleri, B.; Ugliengo, P. Neutral Vs Zwitterionic Glycine Forms at the Water/Silica Interface: Structure, Energies, and Vibrational Features from B3LYP Periodic Simulations. Langmuir 2008, 24, 14027-14034.

(40) Pickard, C. J.; Mauri, F. All-Electron Magnetic Response with Pseudopotentials: NMR Chemical Shifts. Phys. Rev. B 2001, 63, 245101.

(41) Charpentier, T. The PAW/GIPAW Approach for Computing NMR Parameters: A New Dimension Added to NMR Study of Solids. Solid State Nucl. Magn. Reson. 2011, 40, 1-20.

(42) Tielens, F.; Calatayud, M. The Synergistic Power of Theory and Experiment in the Field of Catalysis Preface. Catal. Today 2011, 177, $1-2$

(43) Bonhomme, C.; Gervais, C.; Babonneau, F.; Coelho, C.; Pourpoint, F.; Azais, T.; Ashbrook, S. E.; Griffin, J. M.; Yates, J. R.; Mauri, F.; Pickard, C. J. First-Principles Calculation of NMR Parameters Using the Gauge Including Projector Augmented Wave Method: A Chemist's Point of View. Chem. Rev. 2012, 112, 57335779.

(44) Folliet, N.; Roiland, C.; Begu, S.; Aubert, A.; Mineva, T.; Goursot, A.; Selvaraj, K.; Duma, L.; Tielens, F.; Mauri, F.; Laurent, G.; Bonhomme, C.; Gervais, C.; Babonneau, F.; Azaïs, T. Investigation of the Interface in Silica-Encapsulated Liposomes by Combining Solid State NMR and First Principles Calculations. J. Am. Chem. Soc. 2011 $133,16815-16827$

(45) Kresge, C. T.; Leonowicz, M. E.; Roth, W. J.; Vartuli, J. C.; Beck, J. S. Ordered Mesoporous Molecular-Sieves Synthesized by a LiquidCrystal Template Mechanism. Nature 1992, 359, 710-712.

(46) Beck, J. S.; Vartuli, J. C.; Roth, W. J.; Leonowicz, M. E.; Kresge, C. T.; Schmitt, K. D.; Chu, C. T. W.; Olson, D. H.; Sheppard, E. W.; McCullen, S. B.; Higgins, J. B.; Schlenker, J. L. A New Family of 
Mesoporous Molecular-Sieves Prepared with Liquid-Crystal Templates. J. Am. Chem. Soc. 1992, 114, 10834-10843.

(47) Tielens, F.; Gervais, C.; Lambert, J. F.; Mauri, F.; Costa, D. Ab Initio Study of the Hydroxylated Surface of Amorphous Silica: A Representative Model. Chem. Mater. 2008, 20, 3336-3344.

(48) Metz, G.; Wu, X. L.; Smith, S. O. Ramped-Amplitude CrossPolarization in Magic-Angle-Spinning NMR. J. Magn. Reson., Ser. A 1994, 110, 219-227.

(49) Massiot, D.; Fayon, F.; Capron, M.; King, I.; Le Calve, S.; Alonso, B.; Durand, J. O.; Bujoli, B.; Gan, Z. H.; Hoatson, G. Modelling One- and Two-Dimensional Solid-State NMR Spectra. Magn. Reson. Chem. 2002, 40, 70-76.

(50) Kresse, G.; Hafner, J. Ab-Initio Molecular-Dynamics for LiquidMetals. Phys. Rev. B 1993, 47, 558-561.

(51) Kresse, G.; Hafner, J. Ab-Initio Molecular-Dynamics Simulation of the Liquid-Metal Amorphous-Semiconductor Transition in Germanium. Phys. Rev. B 1994, 49, 14251-14269.

(52) Perdew, J. P.; Burke, K.; Ernzerhof, M. Generalized Gradient Approximation Made Simple. Phys. Rev. Lett. 1996, 77, 3865-3868.

(53) Perdew, J. P.; Burke, K.; Ernzerhof, M. Generalized Gradient Approximation Made Simple (Vol 77, Pg 3865, 1996). Phys. Rev. Lett. 1997, 78, 1396-1396.

(54) Calatayud, M.; Tielens, F.; De Proft, F. Reactivity of Gas-Phase, Crystal and Supported V2O5 Systems Studied Using Density Functional Theory Based Reactivity Indices. Chem. Phys. Lett. 2008, $456,59-63$.

(55) de Bocarme, T. V.; Chau, T. D.; Tielens, F.; Andres, J.; Gaspard, P.; Wang, R. L. C.; Kreuzer, H. J.; Kruse, N. Oxygen Adsorption on Gold Nanofacets and Model Clusters. J. Chem. Phys. 2006, 125.

(56) Tielens, F.; Andres, J.; Chau, T. D.; de Bocarme, T. V.; Kruse, N.; Geerlings, P. Molecular Oxygen Adsorption on Electropositive Nano Gold Tips. Chem. Phys. Lett. 2006, 421, 433-438.

(57) Tielens, F.; Calatayud, M.; Dzwigaj, S.; Che, M. What Do Vanadium Framework Sites Look Like in Redox Model Silicate Zeolites? Microporous Mesoporous Mater. 2009, 119, 137-143.

(58) Tielens, F.; Trejda, M.; Ziolek, M.; Dzwigaj, S. Nature of Vanadium Species in V Substituted Zeolites: A Combined Experimental and Theoretical Study. Catal. Today 2008, 139, 221226.

(59) Blochl, P. E.; Jepsen, O.; Andersen, O. K. Improved Tetrahedron Method for Brillouin-Zone Integrations. Phys. Rev. B 1994, 49, 16223-16233.

(60) Kresse, G.; Joubert, D. From Ultrasoft Pseudopotentials to the Projector Augmented-Wave Method. Phys. Rev. B 1999, 59, 17581775.

(61) Wu, X.; Vargas, M. C.; Nayak, S.; Lotrich, V.; Scoles, G. Towards Extending the Applicability of Density Functional Theory to Weakly Bound Systems. J. Chem. Phys. 2001, 115, 8748-8757.

(62) Grimme, S. Semiempirical GGA-Type Density Functional Constructed with a Long-Range Dispersion Correction. J. Comput. Chem. 2006, 27, 1787-1799.

(63) Giannozzi, P.; Baroni, S.; Bonini, N.; Calandra, M.; Car, R.; Cavazzoni, C.; Ceresoli, D.; Chiarotti, G. L.; Cococcioni, M.; Dabo, I.; Dal Corso, A.; de Gironcoli, S.; Fabris, S.; Fratesi, G.; Gebauer, R.; Gerstmann, U.; Gougoussis, C.; Kokalj, A.; Lazzeri, M.; Martin-Samos, L.; Marzari, N.; Mauri, F.; Mazzarello, R.; Paolini, S.; Pasquarello, A.; Paulatto, L.; Sbraccia, C.; Scandolo, S.; Sclauzero, G.; Seitsonen, A. P.; Smogunov, A.; Umari, P.; Wentzcovitch, R. M. Quantum Espresso: A Modular and Open-Source Software Project for Quantum Simulations of Materials. J. Phys.: Condens. Matter 2009, 21, 395502.

(64) Troullier, N.; Martins, J. L. Efficient Pseudopotentials for PlaneWave Calculations. Phys. Rev. B 1991, 43, 1993-2006.

(65) Kleinman, L.; Bylander, D. M. Efficacious Form for Model Pseudopotentials. Phys. Rev. Lett. 1982, 48, 1425-1428.

(66) Gervais, C.; Dupree, R.; Pike, K. J.; Bonhomme, C.; Profeta, M.; Pickard, C. J.; Mauri, F. Combined First-Principles Computational and Experimental Multinuclear Solid-State NMR Investigation of Amino Acids. J. Phys. Chem. A 2005, 109, 6960-6969.
(67) Gervais, C.; Profeta, M.; Lafond, V.; Bonhomme, C.; Azais, T.; Mutin, H.; Pickard, C. J.; Mauri, F.; Babonneau, F. Combined Ab Initio Computational and Experimental Multinuclear Solid-State Magnetic Resonance Study of Phenylphosphonic Acid. Magn. Reson. Chem. 2004, 42, 445-452.

(68) Wojtaszek, A.; Sobczak, I.; Ziolek, M.; Tielens, F. Gold Grafted to Mesoporous Silica Surfaces, a Molecular Picture. J. Phys. Chem. C 2009, 113, 13855-13859.

(69) Wojtaszek, A.; Sobczak, I.; Ziolek, M.; Tielens, F. The Formation of Gold Clusters Supported on Mesoporous Silica Material Surfaces: A Molecular Picture. J. Phys. Chem. C 2010, 114, 9002-9007.

(70) Islam, M. M.; Costa, D.; Calatayud, M.; Tielens, F. Characterization of Supported Vanadium Oxide Species on Silica: A Periodic DFT Investigation. J. Phys. Chem. C 2009, 113, 1074010746.

(71) Guesmi, H.; Tielens, F. Chromium Oxide Species Supported on Silica: A Representative Periodic DFT Model. J. Phys. Chem. C 2012, $116,994-1001$

(72) Shenderovich, I. G.; Buntkowsky, G.; Schreiber, A.; Gedat, E.; Sharif, S.; Albrecht, J.; Golubev, N. S.; Findenegg, G. H.; Limbach, H. H. Pyridine-N-15 - a Mobile NMR Sensor for Surface Acidity and Surface Defects of Mesoporous Silica. J. Phys. Chem. B 2003, 107, 11924-11939.

(73) Brunauer, S.; Emmett, P. H.; Teller, E. Adsorption of Gases in Multimolecular Layers. J. Am. Chem. Soc. 1938, 60, 309-319.

(74) Barrett, E. P.; Joyner, L. G.; Halenda, P. P. The Determination of Pore Volume and Area Distributions in Porous Substances. 1. Computations from Nitrogen Isotherms. J. Am. Chem. Soc. 1951, 73, 373-380.

(75) Lopes, I.; Piao, L. Y.; Stievano, L.; Lambert, J. F. Adsorption of Amino Acids on Oxide Supports: A Solid-State NMR Study of Glycine Adsorption on Silica and Alumina. J. Phys. Chem. C 2009, 113, 1816318172.

(76) Stievano, L.; Tielens, F.; Lopes, I.; Folliet, N.; Gervais, C.; Costa, D.; Lambert, J.-F. Density Functional Theory Modeling and Calculation of NMR Parameters: An Ab Initio Study of the Polymorphs of Bulk Glycine. Cryst. Growth Des. 2010, 10, 3657-3667.

(77) Azais, T.; Hartmeyer, G.; Quignard, S.; Laurent, G.; TournePeteilh, C.; Devoisselle, J. M.; Babonneau, F. Solid-State NMR Characterization of Drug-Model Molecules Encapsulated in MCM-41 Silica. Pure Appl. Chem. 2009, 81, 1345-1355.

(78) Trebosc, J.; Wiench, J. W.; Huh, S.; Lin, V. S. Y.; Pruski, M. Solid-State NMR Study of MCM-41-Type Mesoporous Silica Nanoparticles. J. Am. Chem. Soc. 2005, 127, 3057-3068.

(79) Duchateau, R.; Dijkstra, T. W.; van Santen, R. A.; Yap, G. P. A. Silsesquioxane Models for Silica Surface Silanol Sites with Adjacent Siloxide Functionalites and Olefin Polymerization Catalysts Thereof. Chem.-Eur. J. 2004, 10, 3979-3990.

(80) Dijkstra, T. W.; Duchateau, R.; van Santen, R. A.; Meetsma, A.; Yap, G. P. A. Silsesquioxane Models for Geminal Silica Surface Silanol Sites. A Spectroscopic Investigation of Different Types of Silanols. J. Am. Chem. Soc. 2002, 124, 9856-9864.

(81) Hemeryck, A.; Motta, A.; Swiatowska, J.; Marcus, P.; Costa, D. Submitted to PhysChemChemPhys, 2012.

(82) Wright, L. B.; Walsh, T. R. Facet Selectivity of Binding on Quartz Surfaces: Free Energy Calculations of Amino-Acid Analogue Adsorption. J. Phys. Chem. C 2012, 116, 2933-2945.

(83) Bouzoubaa, A.; Costa, D.; Diawara, B.; Audiffren, N.; Marcus, P. Insight of DFT and Atomistic Thermodynamics on the Adsorption and Insertion of Halides onto the Hydroxylated $\mathrm{NiO}(111)$ Surface. Corros. Sci. 2010, 52, 2643-2652. 


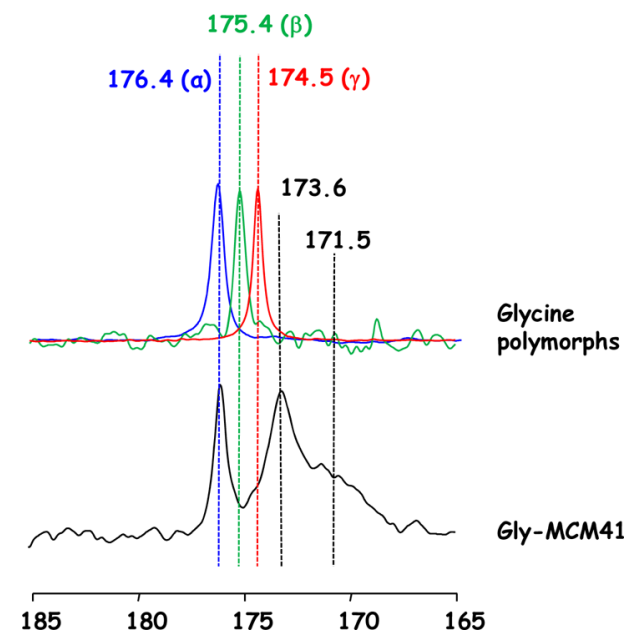

Figure 1. ${ }^{13} \mathrm{C}$ CP MAS NMR spectra of the glycine polymorphs $(\alpha$ glycine, blue; $\beta$-glycine, green; $\gamma$-glycine, red) and Gly/MCM (black line).
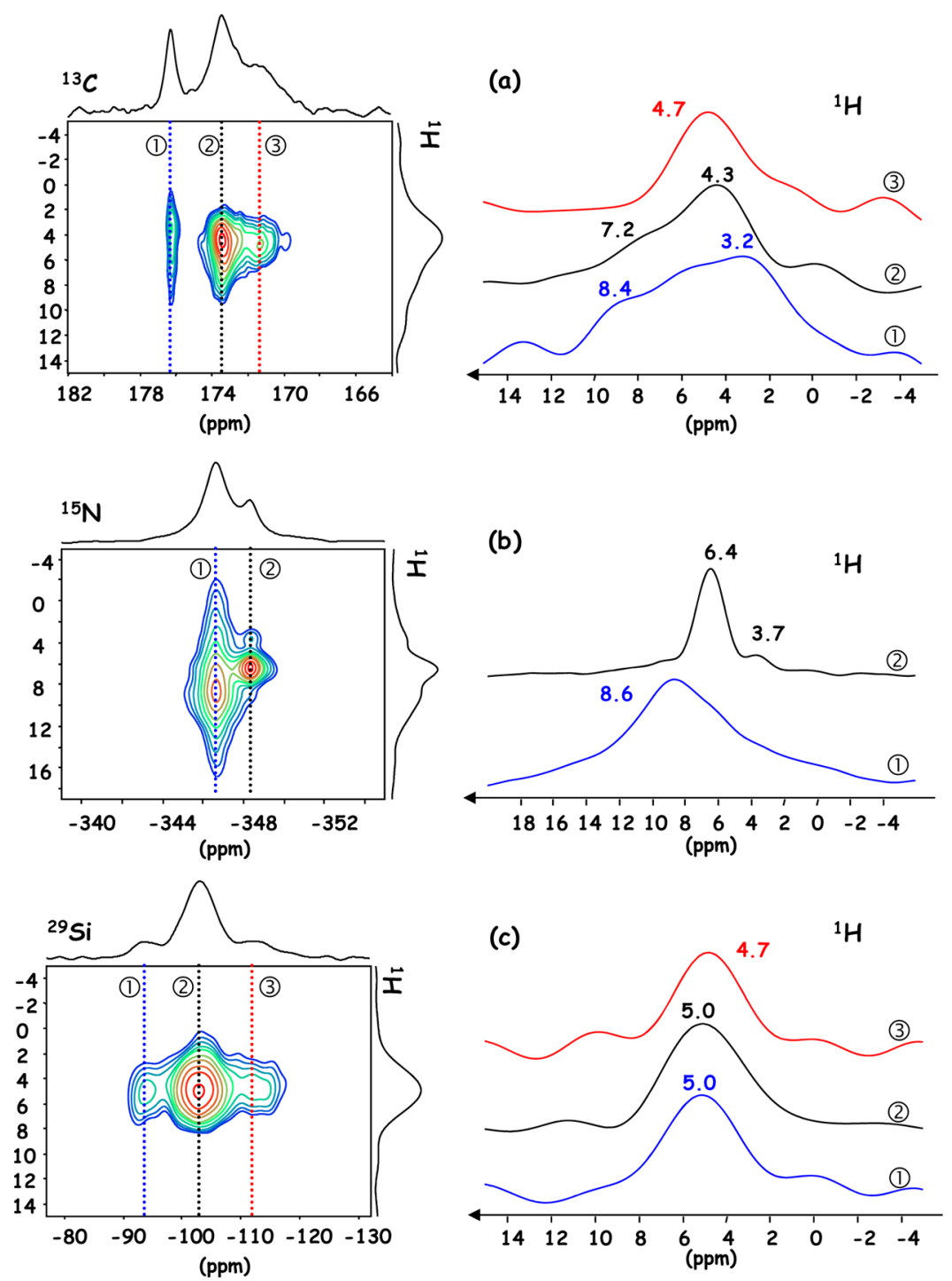

Figure 2. HETCOR CP MAS NMR spectra: (a) ${ }^{13} \mathrm{C}-\left\{{ }^{1} \mathrm{H}\right\}$, (b) ${ }^{15} \mathrm{~N}-\left\{{ }^{1} \mathrm{H}\right\}$, and (c) ${ }^{29} \mathrm{Si}-\left\{{ }^{1} \mathrm{H}\right\}$ of Gly/MCM. ${ }^{1} \mathrm{H}$ projections for specific ${ }^{13} \mathrm{C},{ }^{15} \mathrm{~N}$, or ${ }^{29} \mathrm{Si}$ chemical shifts are presented on the right side of the figure. 


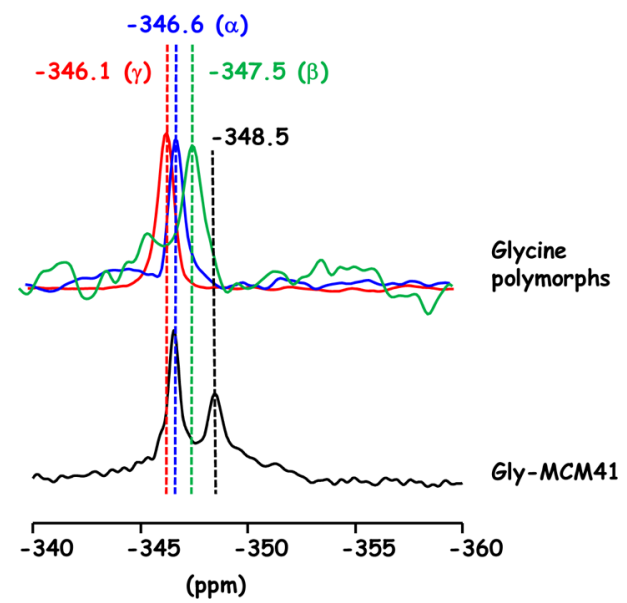

Figure $3 .{ }^{15} \mathrm{~N}$ CP MAS NMR spectra of the glycine polymorphs: $\alpha$ glycine (blue line), $\beta$-glycine (green line), $\gamma$-glycine (red line), and glycine encapsulated in mesoporous silica (black line).

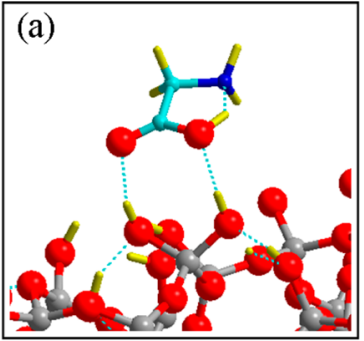

$E_{\text {ads }}=-64 \mathrm{~kJ} / \mathrm{mol}$

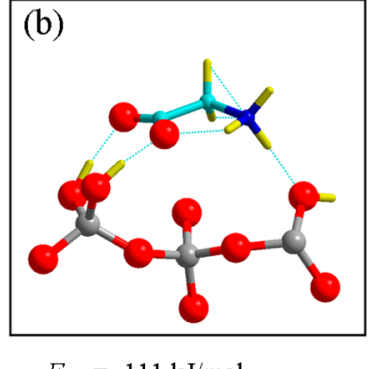

$E_{\text {ads }}=-111 \mathrm{~kJ} / \mathrm{mol}$
Figure 5. Configurations obtained for glycine in interaction with geminal silanols, forming two $\mathrm{H}$-bonds from the $\mathrm{COO}^{-}$end with the geminal pair (a), and an additional bond from the $\mathrm{NH}_{3}{ }^{+}$end with a more distant silanol (b).

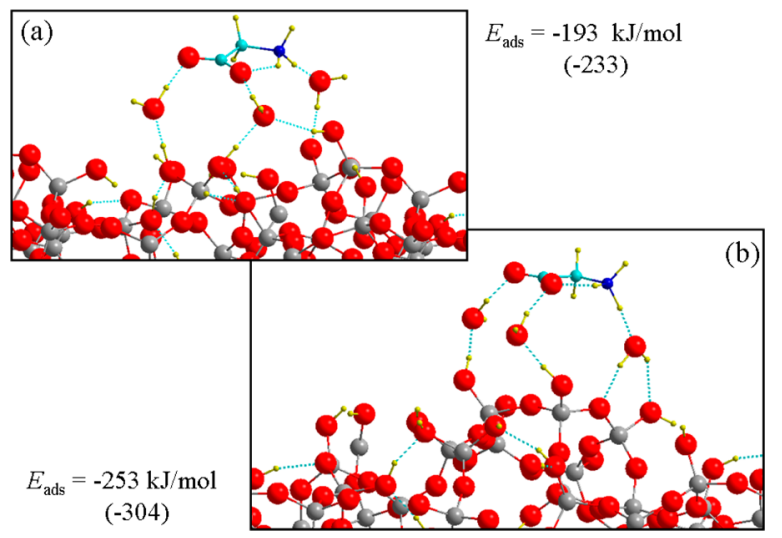

Figure 7. Optimized geometries of glycine coadsorbed with three water molecules on silica (a) on geminal silanols and (b) on a pair of vicinal silanols. (Dispersion corrected energies in parentheses.)
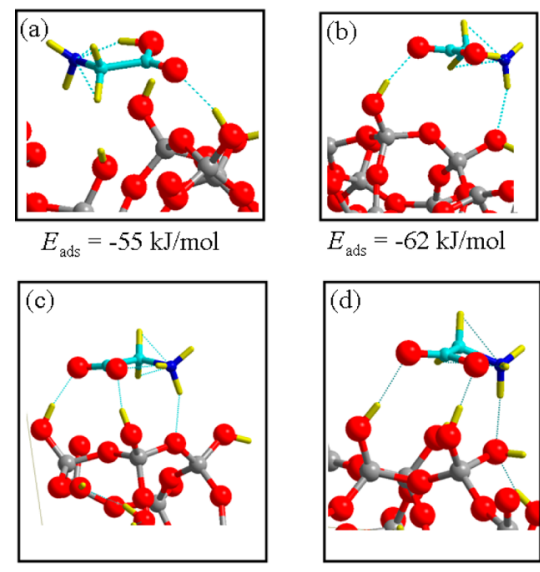

$E_{\text {ads }}=-64 \mathrm{~kJ} / \mathrm{mol}$

$E_{\text {ads }}=-69 \mathrm{~kJ} / \mathrm{mol}$

Figure 4. Configurations obtained for glycine in interaction with a pair of vicinal silanols, forming (a) one H-bond, (b) two H-bonds, and (c,d) three H-bonds with the surface.

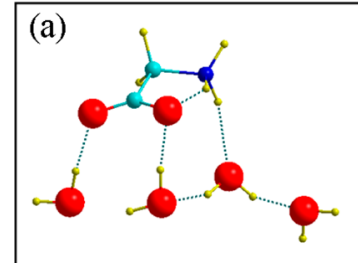

$E_{\text {int }}=-53 \mathrm{~kJ} / \mathrm{mol}$

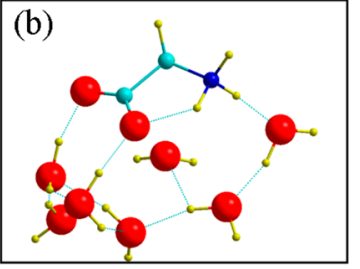

$E_{\text {int }}=-114 \mathrm{~kJ} / \mathrm{mol}$
Figure 6. Configurations corresponding to zwitterionic glycine on silica (Figures $4 \mathrm{e}$ and $5 \mathrm{~b}$ ), but where the $\mathrm{SiOH}$ have been replaced by water molecules, the $\mathrm{O}$ atoms being fixed and the "healing" $\mathrm{H}$ atoms relaxed. The stabilization energy of glycine in those water clusters is given in $\mathrm{kJ} / \mathrm{mol}$.

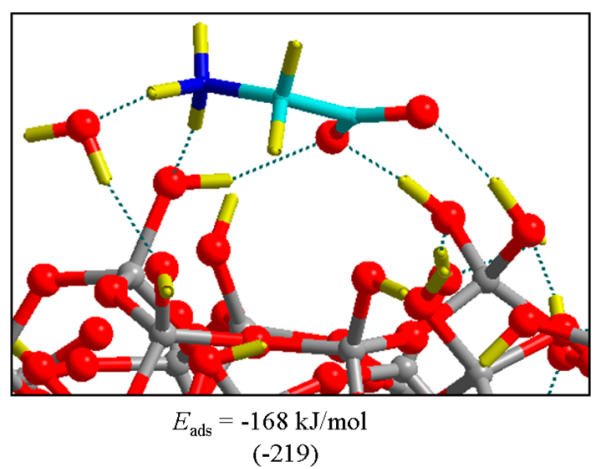

Figure 8. Optimized geometries of glycine coadsorbed with 1 water molecule on silica. (Dispersion corrected energies in parentheses.) 


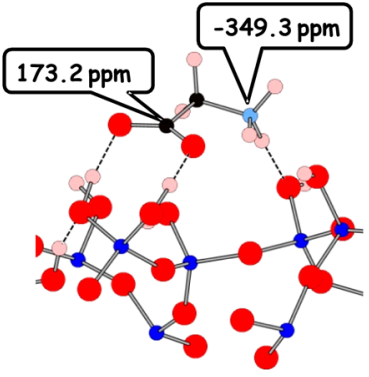

a) Config $I$

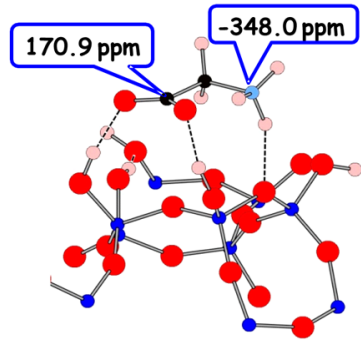

b) Config II

$$
\begin{array}{llll}
0 & \text { Si } & \bullet & C \\
0 & 0 & N \\
0 & H & & \\
\hline
\end{array}
$$

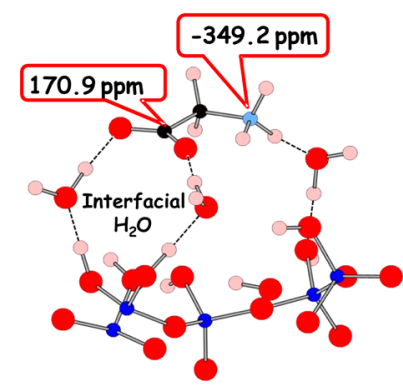

c) Config III

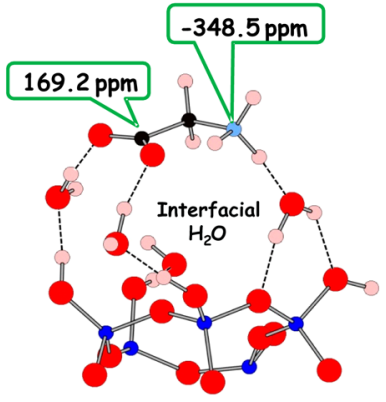

d) Config IV
Figure 9. Calculated ${ }^{13} \mathrm{C}$ et ${ }^{15} \mathrm{~N}$ NMR chemical shift values for various configurations of glycine adsorption on the silica surface: (a) glycine carboxylate in interaction with geminal silanols, (b) glycine carboxylate in interaction with vicinal silanols, (c) glycine carboxylate in interaction with geminal silanols in the presence of interfacial water, and (d) glycine carboxylate in interaction with vicinal silanols in the presence of interfacial water.

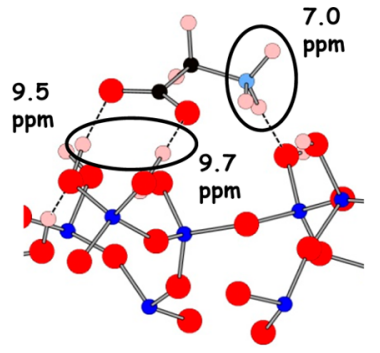

a) Config I

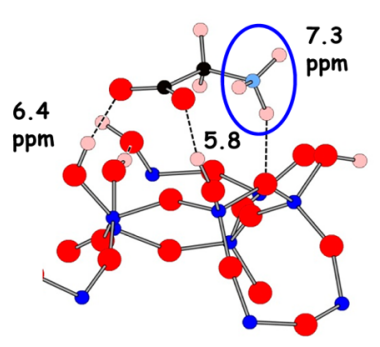

b) Config II

$$
\begin{array}{llll}
\circ & \text { Si } & \bullet & C \\
O & 0 & \circ & N \\
\circ H & &
\end{array}
$$

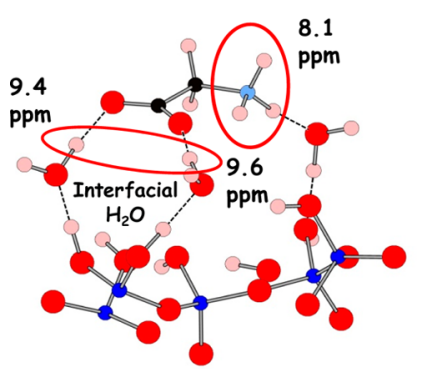

c) Config III

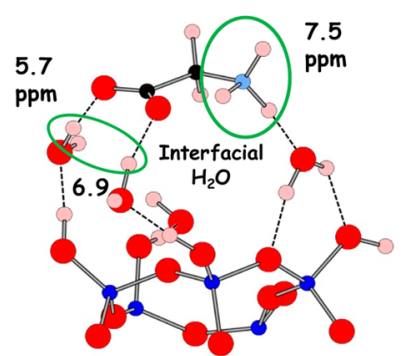

d) Config IV
Figure 11. Calculated ${ }^{1} \mathrm{H}$ NMR parameters of silanols/water molecules in interaction with the carboxylate for various configurations of glycine adsorption on the silica surface: (a) glycine carboxylate in interaction with geminal silanols, (b) glycine carboxylate in interaction with vicinal silanols, (c) glycine carboxylate in interaction with geminal silanols in the presence of interfacial water, and (d) glycine carboxylate in interaction with vicinal silanols in the presence of interfacial water.

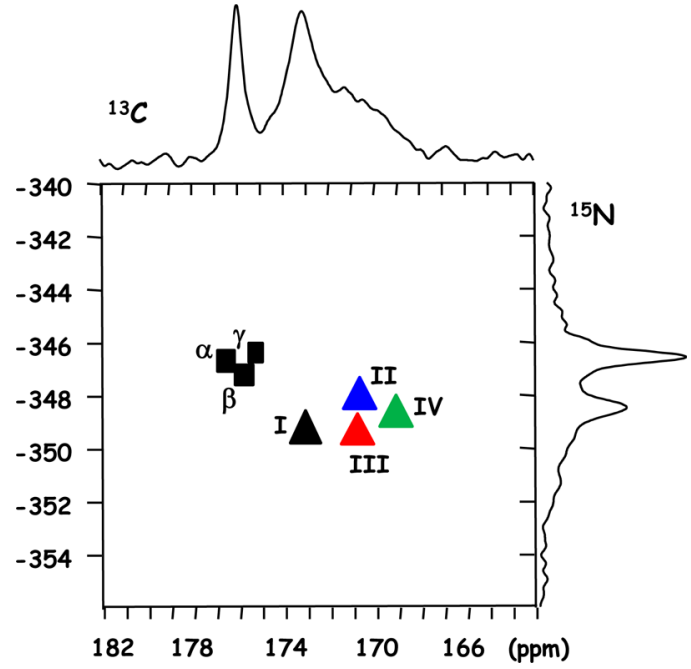

Figure 10. Theoretical two-dimensional map correlating ${ }^{13} \mathrm{C}$ and ${ }^{15} \mathrm{~N}$ spectra of the encapsulated glycine and positioning calculated ${ }^{13} \mathrm{C}$ and ${ }^{15} \mathrm{~N}$ chemical shift values for the different adsorption configurations and for glycine polymorphs. 